\title{
Drivers of Level of Adaptation to Climate Change in Smallholder Farming Systems in Southern Africa: A Multilevel Modeling Approach
}

\author{
Byron Zamasiya, Kefasi Nyikahadzoi, and Billy Billiard Mukamuri
}

\section{Contents}

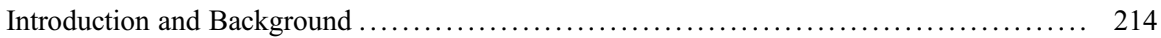

Data Gathering and Analytical Framework ................................... 216

Multilevel Estimation of Determinants of Level of Adaptation ....................... 217

Random Effects ................................................... 217

Hierarchical Linear Regression Model with Random Intercept and Level 2 Covariates ..... 219

Promote Learning Through Linkages with Public and Private Extension Services ......... 222

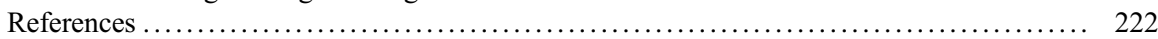

\begin{abstract}
Climate change is a major development challenge affecting developing countries that rely on rain-fed agricultural production for food and income. Smallholder farmers in these countries are using multiple adaptation practices to manage the effects of climate change. This chapter examines household and community-level factors that influence smallholder farmers' level of adaptation to climate change in the Hwedza District in Zimbabwe. Data for this study were collected from 400 randomly selected smallholder farmers, using a structured questionnaire, focus group discussions, and key informant interviews. The study used a multilevel modeling approach to examine the factors that influence smallholder farmers' level of adaptation to climate change. Results from the study show that smallholder farmers' level of adaptation to climate change is conditioned by access to extension services, access to remittances, family labor, household education
\end{abstract}

This chapter was previously published non-open access with exclusive rights reserved by the Publisher. It has been changed retrospectively to open access under a CC BY 4.0 license and the copyright holder is "The Author(s)". For further details, please see the license information at the end of the chapter.

B. Zamasiya $(\bowtie) \cdot$ K. Nyikahadzoi $\cdot$ B. B. Mukamuri Centre for Applied Social Sciences, University of Zimbabwe, Harare, Zimbabwe e-mail: bzamasiya@gmail.com; knyika@gmail.com; bmukamuri@gmail.com 
(household level factors), and linking capital (community-level factor). This chapter therefore concludes that smallholder farmers that have higher levels of adaptation to climate change are those that are well linked to external organizations and have access to agricultural extension services. The chapter recommends that adaptation to climate change can be enhanced by improving access to agricultural extension services and promoting linkages with external organizations that provide information on agricultural adaptation practices.

\section{Keywords}

Level of adaptation $\cdot$ Climate change $\cdot$ Smallholder farmers $\cdot$ Hierarchical linear modeling $\cdot$ Linking capital

\section{Introduction and Background}

Climate change is a major development challenge facing developing countries particularly those in Southern Africa (Ali and Erenstein 2017; IPCC 2014). These countries are battling to address multiple stressors that include a high incidence of poverty, chronic food insecurity, malnutrition, HIV, lack of disaster preparedness, political upheavals, and macroeconomic instability (Adego et al. 2018). In this region, rain-fed agriculture which accounts for $95 \%$ of agricultural production provides livelihoods to over $70 \%$ of the population (Zamasiya and Nyikahadzoi 2018; Asfaw et al. 2016). Overreliance on climate-sensitive agricultural systems exacerbates the vulnerability of countries in Southern Africa such as Zimbabwe (Rurinda et al. 2013). Rainfall is the major determinant of agricultural production. Reports show that the mean annual rainfall has already declined by over $5 \%$ and forecasted to further decrease by $10 \%$. The IPCC's 2018 report notes that with business as usual approach to greenhouse emissions, temperatures will increase by over $1.5^{\circ} \mathrm{C}$. The consequences of such an increase will be catastrophic to resource-constrained smallholder farmers in Southern Africa particularly those with low adaptive capacity. This development will plunge developing countries into dire food insecurity and chronic malnutrition. These conditions require that smallholder farmers who are the major food producers adapt to climate change (Abid et al. 2015; Mabe et al. 2012). Adaptation, in this case, is the use of farming practices that can reduce the impact of climate change on smallholder farmers' food security.

Scholars observe that adaptation reduces the impacts of climate change on food security systems (Adego et al. 2018; Shisanya and Mafongoya 2016; Di Falco et al. 2011). Some of the adaptation practices that smallholder farmers are to manage the impacts of climate change include crop diversification, drought-tolerant varieties, income diversification, staggering of planting dates, crop mixing, and soil and water conservation (Adego et al. 2018; Shisanya and Mafongoya 2016; Nyikahadzoi et al. 2017). Studies show that some smallholder farmers use more than one adaptation practices. In such circumstances, such smallholder farmers are likely to have better food security than those that use solitary adaptation practices. Although adaptation is 
a viable response to climate change, smallholder farmers face challenges in implementing the adaptation practices. These challenges include lack of access to climate information, lack of access to agricultural credit, lack of access to an extension to adequately prepare for seasons, lack of knowledge on adaptation practices, and lack of labor resources (Nyikahadzoi et al. 2017; Salau et al. 2012; Di Falco et al. 2011). Since adaptation differs by contexts, some of the adaptation practices may not be applicable in other regions.

There are very limited studies (Ali and Erenstein 2017; Below et al. 2012) on drivers of the level of adaptation to climate change by smallholders. While the limited studies that are there provide important insights on determinants of the level of adaptation among smallholder farmers, their major challenge is that they used simplistic modeling techniques. These techniques do not recognize the nesting of data in groups and may, therefore, lead to biased results and poor policy targeting. This chapter recognizes that since farmers are nested in villages and villages are nested in wards, the actions of individual smallholder farmers are a function of household socioeconomic level and community-level variables. This is because smallholder farmers live in an open environment in which they interact among themselves, interact with people from other wards, and interact with external organizations. The levels of interaction vary from village to village, and this necessitates the use of multilevel modeling techniques (Frankenberger et al. 2013). The chapter proposes the use of the hierarchical linear modeling technique to examine the drivers of the level of adaptation to climate change among smallholders' farmers in the Hwedza District of Zimbabwe. This model addresses the weaknesses of confounding that are inherent in models used in previous studies.

In some of the studies on drivers of the level of adaptation to climate change, social capital was used as an explanatory variable. The definition used for social capital is restricted to farmer-farmer interactions at a local level such as within a village. This definition does not capture vertical interactions between communities and organizations that are external to the community. In this study, a deliberate attempt is made to distinguish between social capitals. The chapter adopts the categorization of social capital proposed by Aldrich (2012) and Frankenberger et al. (2013) which provides a clear distinction between bonding capital, bridging capital and linking capital. In this study, our concern is on linking social capital. It refers to the linkages between communities and organizations that are external to it. Scholars argue that communities that have better resilience are those that have higher linking social capital compared to bonding capital (Aldrich 2012; Taruvinga et al. 2017). This chapter measures linking capital as a village-level variable and use it as a level 2 covariate in the hierarchical linear regression model.

Given the inevitability of climate change, adequately preparing for this eventuality requires policymakers to understand the drivers of the level of current adaptation practices to climate change by smallholders. The purpose of this chapter is to improve policymakers' understanding of the determinants of smallholder farmers' level of adaptation to climate change. The issue of determinants of the level of adaptation to climate change among smallholder farmers is poorly understood and measured. In this study, the level of adaptation to climate change is the number of 
strategies that are used by a smallholder farmer in response to climate change. This chapter, therefore, seeks to provide empirical evidence on what drives the level of adaptation. This information is critical for identifying and setting policy targets for enhancing adaptation. Without that, it is difficult for policymakers to enhance current and future adaptation by smallholder farmers.

\section{Data Gathering and Analytical Framework}

This study was conducted in Hwedza District in Mashonaland East Province of Zimbabwe is a "climate hotspot." Zimbabwe is divided into five agro-ecological regions known as natural regions (NR). This classification is based on the soil quality, rainfall regime, and vegetation distribution. The quality of the land resource declines from natural region (NR) I through to NR V. Hwedza District is located in natural region II with an annual rainfall of 650-800 $\mathrm{mm}$ and a mean temperature of $29{ }^{\circ} \mathrm{C}$ (Rurinda et al. 2013). The predominant soil type is coarse sandy soils derived from granitic rocks (Rurinda et al. 2014). Average household farm sizes range between 2 and 5 ha per household (Rurinda et al. 2014). Hwedza District is a communal area dominated by subsistence maize production for food security. The subsistence farmers also grow groundnuts, finger millet, and cowpeas on small plots (Zamasiya et al. 2018). Crop production is complemented with livestock rearing mostly cattle, goats, and indigenous chickens. During poor cropping seasons, smallholder farmers in the district rely on non-timber forest products for food (Woittiez et al. 2013) and food aid from nongovernmental organizations (NGO). Due to climate change, the onset and distribution of rainfall in the Hwedza District are now very unpredictable. The district experiences frequent midseason droughts with good rainfall years increasingly becoming fewer over the past 20 years (Rurinda et al. 2014). Smallholder farmers in this district use different farming practices to manage the effects of climate change. These practices include crop diversification, staggering of planting dates, soil and water conservation practices, drought-tolerant varieties, integrated soil fertility management, and crop mixing (Zamasiya et al. 2017). Public and private research organizations and nongovernmental organizations were promoting a basket of ex ante climate adaptation practices to improve smallholder farmers' preparedness to droughts and increased rainfall variability.

The study used a multistage sampling technique to select the study site and the survey respondents. The target population in this study are smallholder farmers practicing crop and/or livestock farming in Hwedza District in Zimbabwe. In stage one, purposive sampling was used to select the Hwedza District in Mashonaland East Province of Zimbabwe. This study site was selected on the basis that it has a high agro-ecological potential and has experienced an increase in extreme climatic events since the year 2000. In stage two, random sampling was used to select Ushe and Dendenyore wards from a total of 22 wards in the district. In stage 3, simple random sampling was used to select 10 villages per ward. Dendenyore ward has 30 villages, and the Ushe ward has 22 villages. In the last stage, the study used simple random sampling to select 20 households in each village. In total, 400 smallholder farmers were interviewed during the survey in February 2015. 
Quantitative and qualitative data used in this study was solicited from smallholder farmers using a structured questionnaire, focus group discussions (FGDs) and key informant interviews. The structured questionnaire collected data on demographic information, strategies used by smallholder farmers to respond to climate change, access to extension, remittances, and challenges experienced by farmers in adapting to climate change. The key informant interviews were conducted with ward level agricultural extension officers (AEOs) and district level extension officers. In total, eight AEOs participated in the key informant interviews. The study also collected data from knowledgeable smallholder farmers. A total of six farmers participated in the key informant interviews. Knowledgeable farmers are smallholders who have at least 30 years of conducting farming activities in the Hwedza district. Purposive sampling was used to select participants for the key informant interviews. Focus group discussions were conducted with smallholder farmers in each village. Each FGD had 12 smallholder farmers (6 males and 6 females). The purpose of FGDs in each village was to get an average rating of the village's perception of the level of linking the capital, the farming practices used by smallholder farmers, and the challenges that they are experiencing in adapting.

Quantitative data analysis was done in STATA Version 15. This study used a multilevel modeling technique that is known as the hierarchical linear modeling (HLM) to establish the determinants of farmers' level of adaptation to climate change. An HLM technique is a random coefficient modeling approach that can be used to analyze data that is nested within groups (Huta 2014). Such models are used to examine how individual-level relationships vary as a function of group characteristics (Hox et al. 2018). The HLM estimation procedures are capable of analyzing nested data (Huta 2014). The results from this analysis are presented in tables as coefficients. This study used a level 2 HLM approach comprising household-level variables for individual farmers and group level variables. Qualitative data collected from interviews and focus group discussions and observations were analyzed thematically.

\section{Multilevel Estimation of Determinants of Level of Adaptation}

This chapter presents the results from the determinants of the level of adaptation to climate change among smallholder farmers in Zimbabwe.

The first stage is to run the random effects model. The purpose of doing this is to understand the portion of variance that is due to cross-village interactions compared to individual household interactions. This model can be written as follows:

\section{Random Effects}

Results in Table 1 show that there are 400 level 1 units (number of observations) in the analysis and 20 level 2 units (number of villages/groups). The cluster size varies from 14 to 28 with a mean cluster size of 20 . The log-likelihood ratio is $-797,1447$. The grand mean across the villages is 1.5066 with a standard error of 0.1640 . The $\mathrm{z}$ 
Table 1 Estimation results for a random effects model

\begin{tabular}{l|l|l|l|l|l|l}
\hline LOA & Coef. & Std. Err. & $\mathrm{Z}$ & $\mathrm{P}>\mathrm{z}$ & {$[95 \%$ Conf. } & Interval $]$ \\
\hline cons & 1.5066 & 0.1640 & 9.1900 & 0.0000 & 1.1851 & 1.8281 \\
\hline Random effects parameters & Estimate & Std. Err. & {$[95 \%$ Conf. Interval $]$} & \\
\hline $\begin{array}{l}\text { village: Identity } \\
\text { var(cons) }\end{array}$ & 0.3868 & 0.1723 & 0.1615 & 0.9263 \\
\hline $\operatorname{var(Residual)~}$ & 2.9565 & 0.2146 & 2.5644 & 3.4085 & \\
\hline
\end{tabular}

LR test versus linear model: chibar2 $(01)=22.5800$ Prob $\geq$ chibar $2=0.0000$

Table 2 Estimation results for a random intercept model

\begin{tabular}{l|l|l|l|l|l|l}
\hline Adaptation (Adj) & Coef. & Std. Err. & $\mathrm{z}$ & $\mathrm{P}>\mathrm{z}$ & {$[95 \%$ Conf. } & Interval] \\
\hline Visitextn & 1.1785 & 0.2022 & 5.8300 & $0.0000 * * *$ & 0.7822 & 1.5748 \\
\hline FamilyRemit & 0.7180 & 0.2262 & 3.1700 & $0.0020 * * *$ & 0.2747 & 1.1612 \\
\hline Farmlabor & 0.1669 & 0.0433 & 3.8500 & $0.0000 * * *$ & 0.0819 & 0.2518 \\
\hline Hheducation & 0.0533 & 0.0316 & 1.6900 & $0.0920 *$ & -0.0087 & 0.1152 \\
\hline $\begin{array}{l}\text { cons } \\
\text { Random effects parameters }\end{array}$ & 0.3953 & 0.2588 & 1.5300 & 0.1270 & -0.1119 & 0.9025 \\
\hline $\begin{array}{l}\text { village: Identity } \\
\text { var(cons) }\end{array}$ & 0.2390 & 0.1193 & 0.0898 & 0.6360 & \\
\hline \\
var(Residual) & 2.6064 & 0.1892 & 2.2608 & 3.0049 & \\
\hline
\end{tabular}

Wald chi2 $(4)=59.92$; Prob $>$ chi2 $=0.0000$; LR test versus linear model: chibar2 $(01)=13.61$ Prob $\geq$ chibar $2=0.0001$

statistic is 9.1900, and the p-value is 0.000 . The reported LR test statistic is 22.5800 with a p-value of 0.000 ; we, therefore, reject the null hypothesis that tao is equal to zero. It, therefore, means that there is intervillage variation in the adaptation by smallholder farmers. Based on the output, the interclass correlation is $11.57 \%$. This means that $11.57 \%$ of the variation in adaptation among smallholder farmers in Hwedza district is due to differences across villages and $88.43 \%$ is due to individual differences across farmers.

The random intercept model involves the addition of level 1 covariates to the model, but it assumes fixed effects. In this stage, the intercept is allowed to vary across villages to accommodate intervillage variations. The model can be expressed as follows:

Table 2 shows the estimation results of the random intercept model. The results show that all the independent variables have positive effects on adaptation. They are all statistically significant with Visitextn $(p<1 \%)$, FamilyRemit $(p<1 \%)$, Farmlabor $(p<1 \%)$, and Hheducation $(p<10 \%)$. The Wald test shows that $\mathrm{W}=59.92$ and $p$-value $=0.0000$. Comparing the fit of the random intercept model and the $\mathrm{LR}=13.61$ and a $p$-value of 0.0001 . Therefore, the null hypothesis that the intercept is the same across all villages is rejected. 


\section{Hierarchical Linear Regression Model with Random Intercept and Level 2 Covariates}

This model seeks to account for the variation in intercepts across villages. This is done by adding a level two covariate.

Table 3 shows the results of the hierarchical linear regression model with random incept and a village-level covariate. The results show that Level 1 covariates are all significant. The level 2 covariate (linking social capital) is also very significant $(p<1 \%)$. The Wald test statistic $\mathrm{W}=100.55$ has a $\mathrm{p}$-value of 0.000 . The results show that the second level variable linking social capital improves the level of adaptation for smallholder farmers.

This chapter presents the discussion from the study. The discussion is based on theoretical and empirical evidence to recommend how government and organizations external to the community can help in improving adaptation to climate change by smallholder farmers. Based on this study, the variables that can be influenced to promote adaptation are access to agricultural extension services, access to remittances, family labor, level of education, and linking social capital.

The coefficient of access to agricultural extension services $(p<1 \%)$ is statistically significant and positively influences smallholder farmers' level of adaptation to climate change. Extension officers play a pivotal role in the dissemination of agricultural adaptation technologies (Zamasiya and Nyikahadzoi 2018; Zamasiya et al. 2014). Through field-based demonstrations and awareness meetings, extension officers help in disseminating information to smallholder farmers on adaptation practices that they can use to manage the impacts of climate change on food security (Zamasiya et al. 2017; Ali and Erenstein 2017). Smallholder farmers who have access to AEOs are more likely to know different adaptation practices. As such they are more likely to have higher levels of adaptation to climate change than their counterparts. However, key informants highlighted that the major challenge facing AEOs is Zimbabwe is lack of motorcycles for improving mobility and contact with

Table 3 Estimation results for HLM with random intercept and level 2 covariates

\begin{tabular}{|c|c|c|c|c|c|c|}
\hline LOA & Coef. & Std. Err. & $Z$ & $\mathrm{P}>\mathrm{Z}$ & \multicolumn{2}{|c|}{ [95\% Conf. Interval] } \\
\hline Extension & 1.0950 & 0.1995 & 5.4900 & 0.0000 & 0.7040 & 1.4859 \\
\hline FamilyRemit & 0.6645 & 0.2234 & 2.9700 & 0.0030 & 0.2267 & 1.1022 \\
\hline Farmlabor & 0.1574 & 0.0428 & 3.6700 & 0.0000 & 0.0735 & 0.2414 \\
\hline Hheducation & 0.0554 & 0.0312 & 1.7800 & 0.0760 & -0.0057 & 0.1165 \\
\hline Linking & 2.1973 & 0.4137 & 5.3100 & 0.0000 & 1.3865 & 3.0081 \\
\hline cons & -0.4074 & 0.2734 & -1.4900 & 0.1360 & -0.9433 & 0.1286 \\
\hline \multicolumn{2}{|c|}{ Random effects parameters } & Estimate & Std. Err. & \multicolumn{3}{|c|}{ [95\% Conf. Interval] } \\
\hline \multicolumn{7}{|c|}{ village: Identity } \\
\hline \multicolumn{2}{|l|}{$\operatorname{var}($ cons $)$} & 0.0216 & 0.0493 & 0.0002 & \multicolumn{2}{|l|}{1.8808} \\
\hline \multicolumn{2}{|c|}{ var(Residual) } & 2.6050 & 0.1890 & 2.2597 & \multicolumn{2}{|l|}{3.0031} \\
\hline
\end{tabular}

Wald chi2 $(5)=100.55$; Prob $>$ chi2 $=0.0000 ;$ LR test versus linear model: chibar2 $(01)=0.23$ Prob $\geq$ chibar $2=0.3150$ 
smallholder farmers. The wards in Hwedza District are so big that it becomes difficult for the AEOs to effectively contact farmers if they are not motorized. Other AEOs highlighted that they have motorcycles but have no access to fuel. This, therefore, makes it difficult for them to dispatch their roles efficiently. During FGDs, smallholder farmers highlighted that the challenge with AEOs is that climate change is a new phenomenon to them. They were advising farmers based on their lived realities. These results corroborate with the findings of Zamasiya et al. (2018), and Ali and Erenstein (2017).

Results show that the coefficient of access to remittances $(p<1 \%)$ is very statistically significant and positively improves a smallholder farmer's level of adaptation to climate change. Remittances improve the number of financial resources that are available to a household (Nyikahadzoi et al. 2013) for purposes of financing transaction costs associated with adaptation to climate change. These costs could include the cost of improved seed, inorganic fertilizers, and herbicides. Zamasiya et al. (2018) note that smallholder farmers with access to remittances are more likely to adapt than their counterparts. They further highlight that some smallholder farmers rely on disposing of small livestock to finance adaptation costs. This is the case in economies such as Zimbabwe where most smallholder farmers have no access to formal banking systems (Nyikahadzoi et al. 2012). With improved access to financial resources, it is more likely that the smallholder farmers will improve their levels of adaptation. During FGDs, smallholder farmers highlighted that their major challenge is lack of agricultural credit. They mentioned that the lack of access to financial resources limited their ability to implement several adaptation practices. For instance, some farmers highlighted that they lacked financial resources to purchase improved seeds, inorganic fertilizers, and herbicides, and this made it difficult to implement several adaptation practices. Some of the smallholder farmers ended up planting recycled maize seeds. Key informants highlighted that when smallholder farmers used recycled seed, they used the wrong seed rate for maize crop. The key informants also highlighted that in most cases, agro-dealers sell only one variety of maize seeds. The smallholder farmers just end up buying the available seed. These results corroborate with the findings of Ali and Erenstein (2017).

Study findings show that the coefficient of family labor positive and statistically significant $(p<1 \%)$ influences a smallholder farmer's level of adaptation to climate change. Labor is a major constraint to adaptation among smallholder farmers (Deressa et al. 2010). The family offers technical and manual skills that are crucial for executing agronomic practices on time. Smallholder farming households that have large pools of labor can spread labor resources across different adaptation practices. Such households can utilize labor-intensive practices such as crop diversification and soil and water conservation practices (Zamasiya et al. 2018). As such, households with higher labor resources are more likely to have higher levels of adaptation than their counterparts. These results corroborate with the findings of Ali and Erenstein (2017).

Research findings show that the coefficient of level of education $(p<10 \%)$ is marginally statistically significant and positively influences a smallholder farmers' level of adaptation to climate change. Zamasiya et al. (2018) note that education 
improves a smallholder farmer's ability to receive, decode, and use the information on adaptation practices. These results suggest that smallholder farmers who are educated are more likely to be aware of climate change, the adaptation practices that they can use, and the benefits of adaptation. It is therefore likely that such smallholder farmers are more likely to have higher levels of adaptation to climate change than their counterparts. During FGDs, it was observed that most educated smallholder farmers were aware of adaptation practices and were proactively seeking more information on the practices from extension officers. Key informants highlighted that educated farmers were willing to experiment with new adaptation practices than uneducated smallholder farmers. Key informants highlighted that the lack of education among smallholder farmers is a major constraint to adaptation. Results corroborate with the findings of Below et al. (2012) and Ali and Erenstein (2017).

Study findings show that the coefficient of linking capital $(p<1 \%)$ is very statistically significant and positively influences the level of adaptation to climate change. Linking social capital is an important driver of the level of adaptation toß climate change by smallholder farmers. As observed by Aldrich (2012), linking capital improves adaptation through the provision of information that is otherwise unavailable. Through vertical relations with organizations external to the community, linking social capital improves access to information that is very important for enhancing adaptation to climate change (Taruvinga et al. 2017; Babaei et al. 2012). Information that communities may access through linking social capital includes improved varieties, yield robustness of such varieties, baskets of adaptation technologies, research results, and opportunities for exchange visits. In the study site, the communities are linked to research institutions that conduct farmer-managed and researcher-managed experiments. The smallholder farmers participate in field days where they get to interact with staff from organizations that play a key role in the agricultural value chain. Through these platforms, smallholder farmers have access to valuable agronomic information that they use for enhancing their adaptation to climate change. During FGDs, smallholder farmers highlighted that external organizations played a pivotal role in the dissemination of information on adaptation practices. The smallholder farmers noted that they were now aware of new crop varieties, their performance under different management regimes, and had acquired invaluable knowledge on different adaptation practices. Key informants highlighted that financial resources were scarce for the Agritex Department. As such, access to linking capital is associated with higher levels of adaptation to climate change.

This chapter sought to understand the determinants of the level of adaptation among smallholder farmers in Southern Africa using the example of the Hwedza district in Zimbabwe. The study used the multilevel modeling approach. Results show that level of education, access to agricultural extension, family labor, and access to remittances positively influence the level of adaptation. At a community level, adaptation is influenced by access to linking social capital. We, therefore, conclude that smallholder farmers that have a high level of adaptation to climate change are those that are well linked to external organizations and have access to extension services and financial resources. 


\section{Promote Learning Through Linkages with Public and Private Extension Services}

Based on the results from this study, the chapter recommends that to improve smallholder farmers' level of adaptation to climate change, there is a need to enhance access to agricultural extension services and NGOs or research organizations. Because the mobility of extension staff is a recurrent problem in most areas, the public extension should establish linkages with other extension service providers in their area such as NGOs and private companies so that they can combine their programs. This will ease the mobility challenges. Further, government can also boost extension service delivery through timely recruitment, periodic training of the agents, and provision of adequate logistical support. The role of organizations that are external to the smallholder farming communities cannot be underestimated. These institutions provide a feedback loop between grassroots and policymakers. They gather critical information on climate change technologies and disseminate it to smallholder farmers. For instance, NGOs and research organizations have pioneered agricultural technologies and trainings that have since been incorporated into the public extension system. To promote development of linking capital, policymakers need to adopt participatory and inclusive decision-making processes in their work with communities, encourage smallholder farmers to work in groups, promote look and learn tours to other communities to challenge, inspire, and educate communities. This will improve access to critical information on agricultural technologies that are useful for enhancing smallholder adaptation to climate change.

Acknowledgments The authors would like to thank the International Foundation for Science who provided funding for this research through Grant No. S/5158-1.

\section{References}

Abid M, Scheffran J, Schneider U, Ashfaq (2015) Farmers' perceptions of and adaptation strategies to climate change and their determinants: the case of Punjab province, Pakistan. Earth Syst Dyn $6: 225$

Adego T, Simane B, Woldie G (2018) The impact of adaptation practices on crop productivity in Northwest Ethiopia: an endogenous switching estimation. Dev Stud Res 6(1):129-141

Aldrich DP (2012) Building resilience: social capital in post-disaster recovery. University of Chicago Press, Chicago

Ali A, Erenstein O (2017) Assessing farmer use of climate change adaptation practices and impacts on food security and poverty in Pakistan. Clim Risk Manag 16:183-194

Asfaw S, Di Battista F, Lipper L (2016) Agricultural technology adoption under climate change in the Sahel: micro-evidence from Niger. J Afr Econ 25(5):637-669

Babaei H, Gill S, Ahmad N (2012) Bonding, bridging and linking social capital and psychological empowerment among squatter settlements in Tehran, Iran. J Basic Appl Sci Res 2(2):109-115

Below TB, Mutabazi KD, Kirschke D, Franke C, Sieber S, Siebert R, Tscherning K (2012) Can farmers' adaptation to climate change be explained by socio-economic household-level variables? Glob Environ Chang 22(1):223-235 
Deressa T, Hassan R, Ringler C (2010) Perception and adaptation to climate change: the case of farmers in the Nile Basin of Ethiopia. J Agric Sci 149:23-31

Di Falco S, Veronesi M, Yesuf M (2011) Does adaptation to climate change provide food security? A micro-perspective from Ethiopia. Am J Agr Econ 93(3):829-846

Frankenberger T, Mueller M, Spangler T, Alexander S (2013) Community resilience: conceptual framework and measurement feed the future learning agenda. Westat: United States Agency for International Development (USAID), Rockville

Hox J, Moerbeek M, van de Schoot R (2018) The basic two-level regression model. In: Multilevel analysis. Techniques and applications. Routledge, New York

Huta V (2014) When to use hierarchical linear modeling. Tutor Quant Methods Psychol 10 (1): $13-28$

IPCC (2014) Climate Change 2014: Synthesis Report. Contribution of Working Groups I, II and III to the Fifth Assessment Report of the Intergovernmental Panel on Climate Change [Core Writing Team, RK Pachauri and LA Meyer (eds)]. IPCC, Geneva, Switzerland, $151 \mathrm{pp}$

Mabe F, Sarpong D, Osei-Asare Y (2012) Adaptive capacities of farmers to climate change adaption strategies and their effects on rice production in the Northern Region of Ghana. Russ J Agric Socio-Econ Sci 11(11):9-17

Nyikahadzoi K, Siziba S, Mango N, Mapfumo P, Adekunle A, Oluwole F (2012) Creating food selfreliance among the smallholder farmers of eastern Zimbabwe: exploring the role of integrated agricultural research for development. J Food Secur 4:647-656

Nyikahadzoi K, Zamasiya B, Muchinako G, Dziro C (2013) Enhancing social support system for improving food security among the elderly headed household in communal areas of Zimbabwe. J Food Res 2(3):46-54

Nyikahadzoi K, Mombo O, Zamasiya B, Warinda P (2017) Enhancing household food security under changing climatic conditions: a case study of Gokwe North and Hurungwe Districts in Zimbabwe. J Agric Food Inf 18(2):96-109

Rurinda J, Mapfumo P, van Wijk MT, Mtambanengwe F, Rufino MC, Chikowo R, Giller KE (2013) Managing soil fertility to adapt to rainfall variability in smallholder cropping systems in Zimbabwe. Field Crop Res 154:211-225

Rurinda J, Mapfumo P, van Wijk M, Mtambanengwe F, Rufino M, Chikowo R, Giller K (2014) Sources of vulnerability to a variable and changing climate among smallholder households in Zimbabwe: a participatory analysis. Clim Risk Manag 3:65-78

Salau ES, Onuk EG, Ibrahim A (2012) A micro-econometric analysis of adapting portfolios to climate change: adoption of agricultural systems in Latin America. J Agric Ext 16(2):199-211

Shisanya S, Mafongoya P (2016) Adaptation to climate change and the impacts on household food security among rural farmers in uMzinyathi District of Kwazulu-Natal, South Africa. Food Secur 8:597-608

Taruvinga B, Ndou P, Hlerema I, Maraganedzha T, Du Plooy P, Venter S (2017) Fostering linking social capital for successful agricultural development projects in South Africa. Agrekon 56(1):28-39

Woittiez LS, Rufino MC, Giller KE, Mapfumo P (2013) The use of woodland products to cope with climate variability in communal areas in Zimbabwe. Ecol Soc 18(4):24

Zamasiya B, Nyikahadzoi K (2018) Intensification of soybean cultivation by smallholders: opportunities and constraints. In: Nguyen H (ed) Special issue on cultivation of soybeans, vol 1. Burleigh Dodds Science Publication, Cambridge, UK, pp 305-316

Zamasiya B, Mango N, Nyikahadzoi K, Siziba S (2014) Determinants of soybean market participation by smallholder farmers in Zimbabwe. J Dev Agric Econ 6(2):49-58

Zamasiya B, Nyikahadzoi K, Mukamuri BB (2017) Factors influencing smallholder farmers' behavioral intention towards adaptation to climate change in transitional climatic zones: a case study of Hwedza District in Zimbabwe. J Environ Manag 198:233-239

Zamasiya B, Nyikahadzoi K, Mukamuri B (2018) Drivers of adaptation to climate change by smallholder farmers residing in Zimbabwe's communal areas: a case study of Hwedza District in Zimbabwe. Zambezia J Human 45(ii):75-92 
Open Access This chapter is licensed under the terms of the Creative Commons Attribution 4.0 International License (http://creativecommons.org/licenses/by/4.0/), which permits use, sharing, adaptation, distribution and reproduction in any medium or format, as long as you give appropriate credit to the original author(s) and the source, provide a link to the Creative Commons license and indicate if changes were made.

The images or other third party material in this chapter are included in the chapter's Creative Commons license, unless indicated otherwise in a credit line to the material. If material is not included in the chapter's Creative Commons license and your intended use is not permitted by statutory regulation or exceeds the permitted use, you will need to obtain permission directly from the copyright holder.

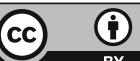

